\title{
EL NIÑO-SOUTHERN OSCILLATION INFLUENCES ON RICE PRODUCTION IN SRI LANKA
}

\author{
LAREEF ZUBAIR* \\ International Research Institute for Climate Prediction, Lamont Doherty Earth Observatory of Columbia University, PO Box 1000, New \\ York 10964-8000, USA \\ Received 14 December 2000 \\ Revised 17 July 2001 \\ Accepted 22 July 2001
}

\begin{abstract}
Despite advances in the capacity to predict the evolution of the El Niño-southern oscillation (ENSO) phenomenon and advances in understanding the influence of ENSO on rainfall in tropical regions such as Sri Lanka, there has been limited use of climate predictions for agricultural decision-making. Climatic fluctuations have a profound influence on the cultivation of crops such as rice, which is the staple food in Sri Lanka. Here, the relationship between the sea-surface temperature-based ENSO index of NINO3.4, rainfall and the departure of Sri Lankan rice production from long-term trends, is analysed for the 'Maha' (October to March) and 'Yala' (April to September) cultivation seasons between 1952 and 1997.

During the El Niño phase, the Maha rice production frequently increased (10 out of 15 seasons) and the Yala production frequently decreased (10 out of 14 seasons). Conversely, during the La Niña phase, the Maha production decreased (seven out of ten seasons) and Yala production increased (six out of eight seasons). Floods, state interventions, civil disturbances, fertilizer price hikes and extreme anomalies in the previous season were noted in the majority of seasons in which these ENSO-production linkages were violated.

The correlation of the Maha rice production anomaly with the average NINO3.4 from October to December was significant at the 5\% level and that with the aggregate October to December rainfall was significant at the $1 \%$ level. Yala rice production showed a significant relationship with concurrent NINO3.4 and a strong correlation $(r=0.60)$ with the previous season's rainfall. Yala cultivation is water constrained, and carryover storage from the previous season is often used to determine the extent of planting.

The relationships between ENSO and seasonal rice production and the relationship between Yala rice production and previous Maha rainfall could be used for agricultural management and policy formulation. Copyright (C) 2002 Royal Meteorological Society.
\end{abstract}

KEY WORDS: Sri Lanka; monsoon; statistical analysis; rainfall; ENSO; agriculture; rice

\section{INTRODUCTION}

In recent decades there has been progress in predicting the evolution of the El Niño-southern oscillation (ENSO) phenomena in the Pacific Ocean (Cane and Zebiak, 1985). ENSO is a shift in the pattern of oceanic warming and atmospheric circulation that typically recurs every 2 to 7 years. Anomalously warm sea surface temperatures in the equatorial Eastern Pacific is referred to as the El Niño phase and its cold analogue is referred to as La Niña. Based on advances in understanding ENSO, seasonal climate forecasts are being issued regularly (e.g. see http://iri.ldeo.columbia.edu/climate/forecasts/). It has been anticipated that these forecasts may be applied to societal benefit to manage agriculture, food security and water resources better.

In addition to advances in predicting ENSO, teleconnections between sea surface temperatures over various regions of the world and climatic anomalies have also been identified (e.g. Ropelewski and Halpert, 1987).

* Correspondence to: Lareef Zubair, International Research Institute for Climate Prediction, Lamont Doherty Earth Observatory of Columbia University, PO Box 1000, New York 10964-8000, USA; e-mail: lareef@iri.columbia.edu 
The relationship between ENSO extremes and rainfall in Sri Lanka has been recognized for two decades (Rasmussen and Carpenter, 1983, Ropelewski and Halpert, 1987, 1989; Suppiah and Yoshino, 1986; Suppiah 1997, 1998; Kane, 1998; Sumathipala and Punyadeva, 1998; Punyawardena and Cherry, 1999). A linkage between agricultural production and ENSO has been established in India (Parathasarthy et al., 1988; Gadgil, 1996), Zimbabwe (Cane et al., 1994; Phillips et al., 1998), the southeastern USA (Hansen et al., 1998) and elsewhere. However, the link between agricultural production, ENSO and rainfall in Sri Lanka has not been examined so far.

Rice is the staple food in Sri Lanka and it is cultivated by farmers on a small-scale in rural regions, principally in the northern and eastern plains (Figure 1). Rice production is acutely dependent on rainfall and farmers use various empirical techniques, such as the sighting of the migrant Grey Wagtail bird to anticipate rain. The principal cultivation season is known as 'Maha' and is from October to March. During this season, there is usually enough water to sustain the cultivation of all rice fields. The subsidiary cultivation season, known as 'Yala' is from April to September. Usually there is only enough water for cultivation of half of the land area compared to that for Maha (Department of Census and Statistics, 1991). There is also variability in the sowing dates and duration of cultivation within the island (Yoshino and Suppiah, 1983).

There has been a steady increase in rice production in Sri Lanka from 1950 to 1990, leading to near self-sufficiency in feeding the population of 20 million. This rise has been attributed to increased area under cultivation, increased irrigation, improved seed varieties, increased fertilizer application and higher purchase prices for rice. Leaker (1984) reports that technological factors, such as transplanting rice, fertilizer, and

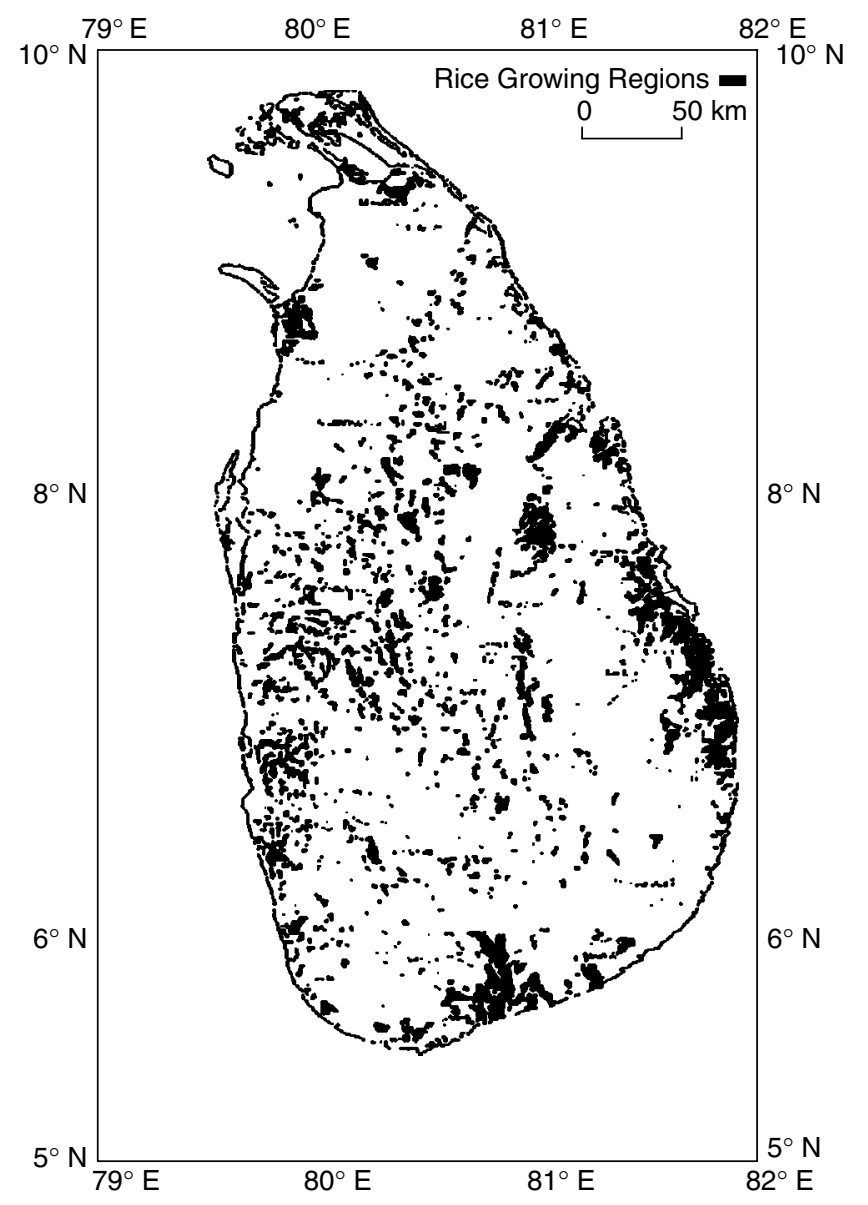

Figure 1. The rice-producing regions of Sri Lanka (shaded) 
irrigation, have had a greater influence on rice yields than climatic variables. However, rainfall variations are a principal factor that affects the inter-annual variability of rice production as distinguished from its long-term trends (Yoshino et al., 1983; Suppiah and Yoshino, 1986).

The objective for this paper is to investigate the link between ENSO, climate variability and the production of rice. The data and methods used are described in Section 2. The results from the analysis are described in Section 3. The conclusions and the implications of these findings for agricultural policy-making and management are discussed in Section 4.

\section{DATA AND METHODS}

\section{ENSO identification}

The El Niño and La Niña years were identified following Trenberth (1997) in the following manner: El Niño conditions persist when the average sea surface temperature in the NINO3.4 area of the equatorial Eastern Pacific Ocean $\left(5^{\circ} \mathrm{N}-5^{\circ} \mathrm{S}, 120-180^{\circ} \mathrm{W}\right)$ exceeds a threshold of $0.4^{\circ} \mathrm{C}$. The sea surface temperatures were obtained from the estimates of Kaplan et al. (1998). La Niña conditions are associated with the NINO3.4 index being below $-0.4^{\circ} \mathrm{C}$. Maha and Yala seasons were associated with El Niño and La Niña when the NINO3.4 values surpassed their respective thresholds during at least three consecutive months of the 6 month long season (Table I).

\subsection{Rainfall in rice-producing regions in Sri Lanka}

The climate of Sri Lanka is tropical, with only a modest seasonal variation in temperature (Domroes, 1974). The island has been divided into three principal agro-climatic zones (Figure 2), viz. wet, intermediate and dry zones, which have been demarcated based on hydrology, meteorology, soils and vegetation (Somasekeram et al., 1988). The wet zone receives an annual rainfall of more than $2500 \mathrm{~mm}$; the intermediate zone receives between 1750 and $2500 \mathrm{~mm}$; and the dry zone receives less than $1750 \mathrm{~mm}$ a year. A district-level analysis of

Table I. Maha (October to March) and Yala (April to September) seasons that are associated with El Niño and La Niña based on the sea surface temperature in the NINO3.4 region of the equatorial Eastern Pacific Ocean

\begin{tabular}{lcccc}
\hline & & & \multicolumn{2}{c}{ Mala } \\
\cline { 5 - 5 } El Niño & La Niña & & El Niño & La Niña \\
\hline $1951-52$ & $1954-55$ & 1953 & 1954 \\
$1957-58$ & $1955-56$ & 1957 & 1955 \\
$1963-64$ & $1964-65$ & 1963 & 1956 \\
$1965-66$ & $1970-71$ & 1965 & 1964 \\
$1968-69$ & $1973-74$ & 1969 & 1971 \\
$1969-70$ & $1974-75$ & 1972 & 1974 \\
$1972-73$ & $1975-76$ & 1982 & 1975 \\
$1976-77$ & $1984-85$ & 1983 & \\
$1977-78$ & $1988-89$ & 1987 & \\
$1979-80$ & $1995-96$ & 1991 & \\
$1982-83$ & & 1992 & \\
$1986-87$ & & 1993 & \\
$1987-88$ & & 1994 & \\
$1991-92$ & & 1997 & \\
$1994-95$ & & &
\end{tabular}




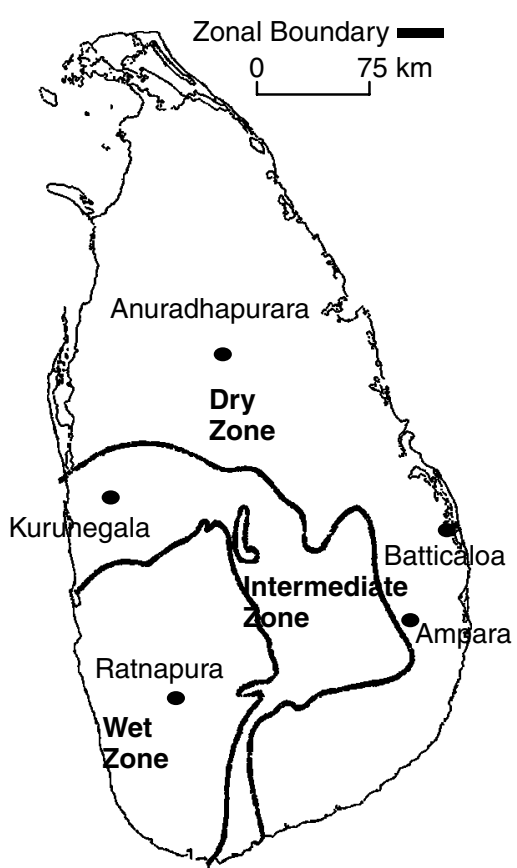

Figure 2. The agro-ecological zones of Sri Lanka (Somasekeram et al., 1988) are shown, along with the rainfall stations that were used in this study

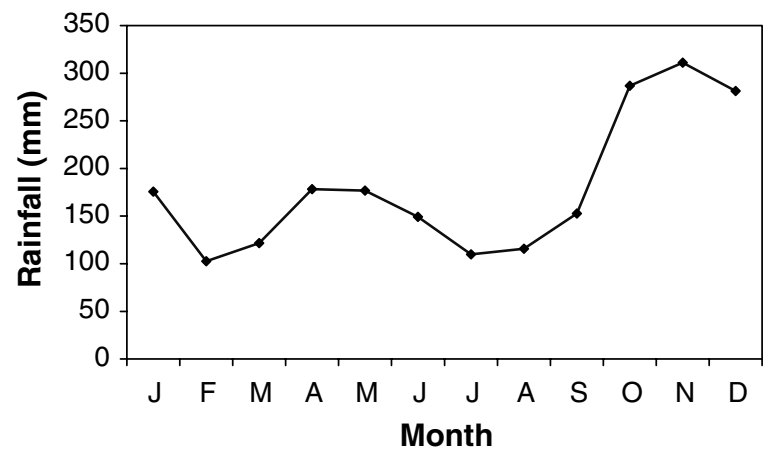

Figure 3. The rainfall climatology in the rice-producing areas of Sri Lanka computed with data from 1869 to 1998

rice production shows that the contributions to the island-wide rice production from the dry, intermediate and wet zone districts are in the ratio $3: 1: 1$.

The rainfall records from five stations located in rice-growing areas were used to compute a rainfall index for rice production in Sri Lanka. In keeping with the proportion of rice fields in the dry zone of the island, three rainfall-measuring stations were selected in the dry zone at Anurhadhapura, Batticaloa and Amparai (Figure 2). The fourth rainfall-measuring station was chosen in the intermediate zone, at Kurunegala, and the fifth station was chosen from the wet zone, at Ratnapura. The records from these five stations are archived by the World Meteorological Organization and are subject to quality control by the Department of Meteorology, Sri Lanka. The average of the rainfall in these five stations was taken as a representative index for rainfall. The annual climatology for this rainfall index (Figure 3) shows a bimodal variation, with one mode peaking in May and the other in November. The two cultivation seasons commence with these peaks. 

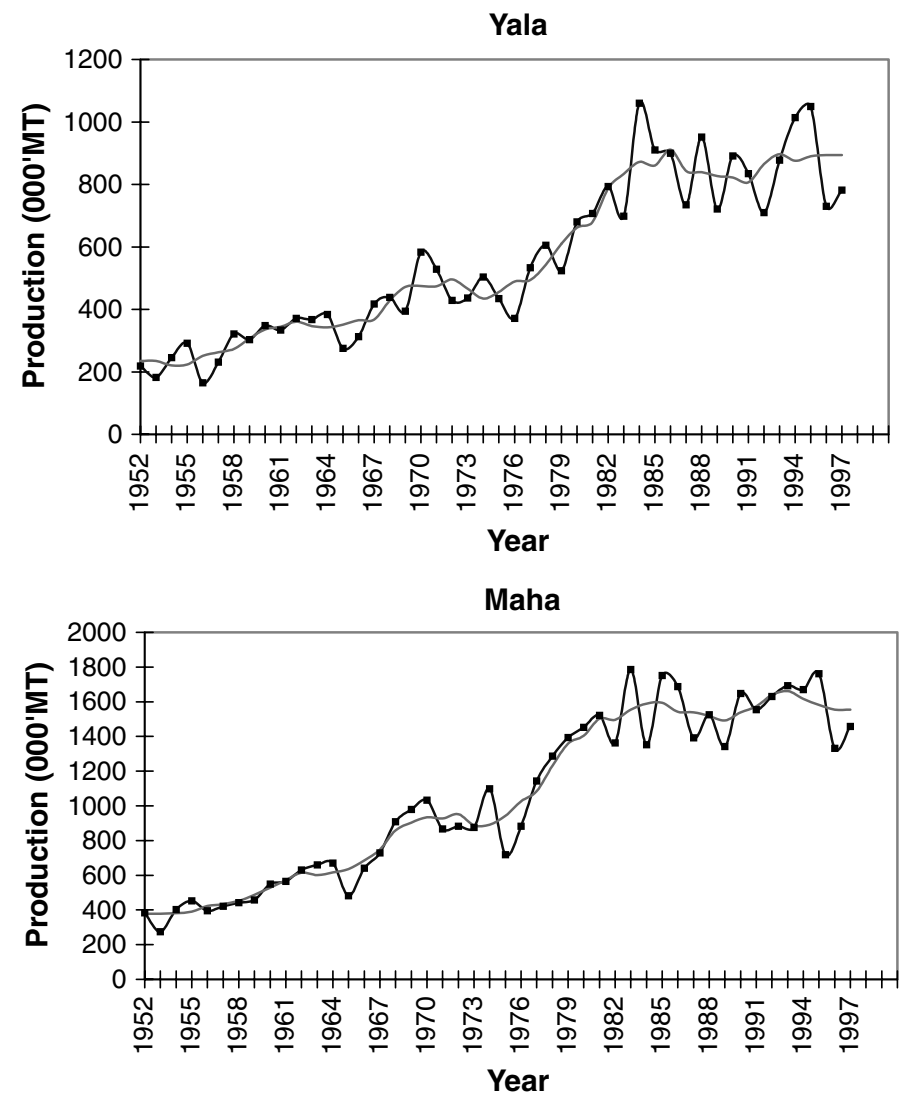

Figure 4. The inter-annual variation of rice production in Sri Lanka during Maha and Yala and its 5 year running mean

\subsection{Rice production}

The long-term trend for both Maha and Yala rice production (Figure 4) shows a steady increase from 1952 to 1983. The reason for the decline in yield from 1989 to 1992 was the withdrawal of the subsidy given for fertilizer purchases by farmers (Seneviratne and Van Holm, 1996). Cultivation was affected in the northern regions of the island after 1983 due to civil disturbances. In addition, a declining trend in Maha rainfall contributed to the declining production trends. The mean Maha rainfall from 1983-1997 was $1110 \mathrm{~mm}$, compared with $1233 \mathrm{~mm}$ from 1952 to 1982 . However, the declining rainfall trends was not the only cause of declining production; a similar analysis for Yala shows that, although rainfall did not drop, there was a decline in production from 1983 to 1997.

For this analysis, the seasonal production anomaly is computed as the difference between the rice production in a given year and the running mean computed for a 5 year window centred on that year. The fractional production anomaly is the production anomaly normalized by the running-mean production for a given year. The yield has been estimated as the ratio of the aggregate seasonal production and the area that was cultivated. The yield too shows an increasing long-term trend, and the yield anomaly is computed in the same manner as the production anomaly.

\section{RESULTS}

\subsection{ENSO and rainfall variability}

The Maha rainfall (Figure 5) varied between a minimum of $702 \mathrm{~mm}$ in 1993-94 and a maximum of $1885 \mathrm{~mm}$ in 1957-58, with an average of $1278 \mathrm{~mm}$. During El Niño years, the rainfall in the first 3 months 


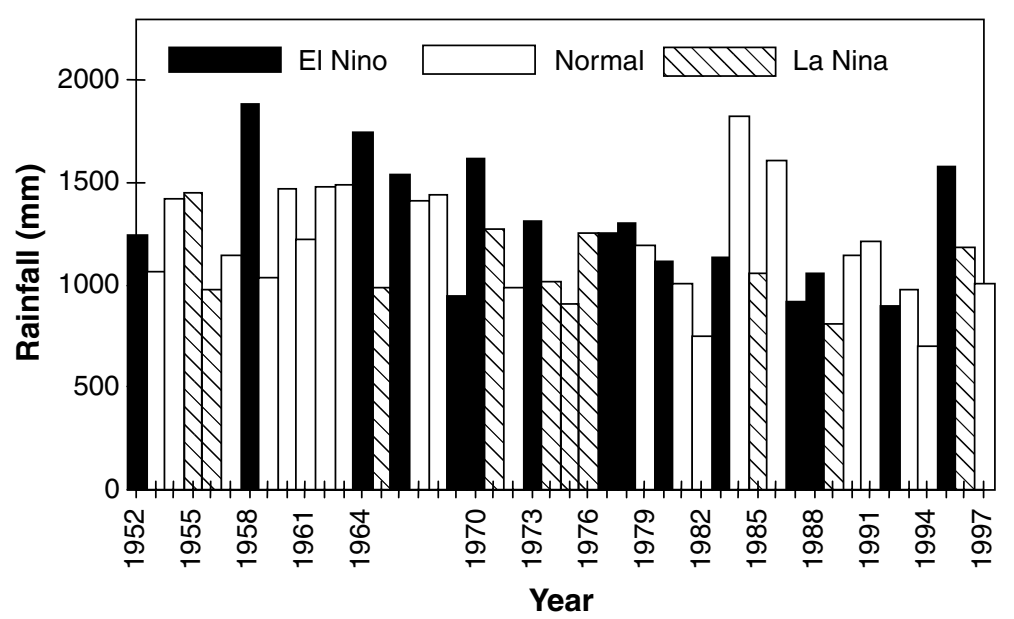

Figure 5. The average rainfall in rice-producing areas of Sri Lanka during the Maha season. Maha starts in the previous October and continues to the March of the indicated year

Table II. Average seasonal rainfall for Sri Lanka in the rice farming areas during all years and El Niño and La Niña seasons for the period from 1952 to 1997 . The percentage departure from average is provided in parentheses

\begin{tabular}{llccc}
\hline & & \multicolumn{3}{c}{ Rainfall $(\mathrm{mm})$} \\
\cline { 3 - 5 } & & All years & El Niño & La Niña \\
\hline \multirow{2}{*}{ Maha } & ONDJFM & 1278 & $1320(+3 \%)$ & $1196(-7 \%)$ \\
& OND & 878 & $998(+14 \%)$ & $783(-11 \%)$ \\
& JFM & 400 & $323(-19 \%)$ & $413(+3 \%)$ \\
& AMJJAS & 883 & $898(+2 \%)$ & $931(+5 \%)$ \\
& AMJ & 505 & $543(+8 \%)$ & $494(-2.2 \%)$ \\
& JAS & 378 & $355(-6 \%)$ & $437(16 \%)$ \\
\hline
\end{tabular}

of Maha rises by $14 \%$ on average and declines by $19 \%$ during the last 3 months (Table II). The October to December (OND) rainfall and NINO3.4 were correlated $(r=0.51)$ at the $1 \%$ level. These changes to the rainfall pattern aid rice cultivation, as rainfall is required for rice in the early months after planting. Usually, rice varieties that mature in 4 to 5.5 months are sown in this season.

The Yala rainfall (Figure 6) had a maximum of $1212 \mathrm{~mm}$ in 1959, a minimum of $541 \mathrm{~mm}$ in 1976 and an average of $883 \mathrm{~mm}$ (Table II). During El Niño years, there was enhanced rainfall in May and a decline in rainfall during July and August (Figure 7). The late Yala (July-September (JAS)) rainfall during La Niña years increased by $16 \%$ compared with that during all years (Table II).

\subsection{Rice production variability in Maha}

The Maha rice production anomaly (Figure 8 ) shows a high correlation $(r=0.46)$ with the OND rainfall and a modest correlation ( $r=0.29$ ) with the OND NINO3.4 (Table III). Both OND rainfall and rice production were higher in 10 out of the $15 \mathrm{El}$ Niño years (Table IV and Figure 6). Floods were reported in three of the five exceptional years (1957-58, 1965-66 and 1972-73) and production dropped (Central Bank, 1958, 1966, 1973). The decreases in production in the remaining two exceptional El Niño Maha seasons (1986-87 and 1991-92) are due to a decline in rainfall.

During La Niña episodes, the rainfall in the first half of Maha declined by $11 \%$. There was a drop in rainfall in seven out of ten La Niña Maha seasons. The exceptions were 1954-55, 1973-74 and 1984-85. 


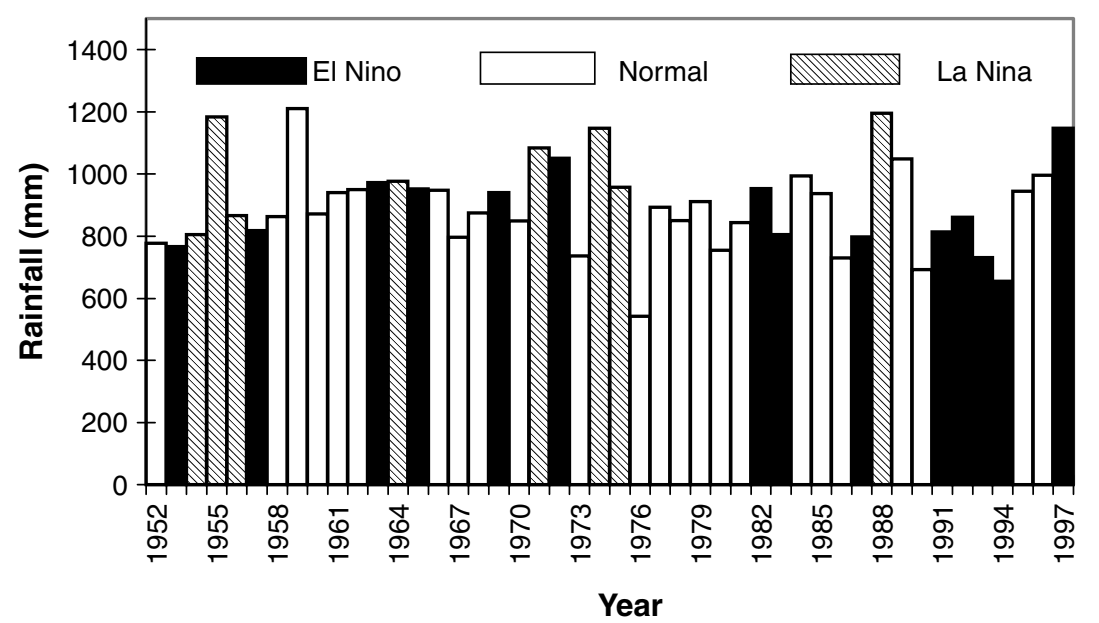

Figure 6. The average rainfall in rice-producing areas in Sri Lanka during the Yala season computed as the aggregate rainfall from April to September

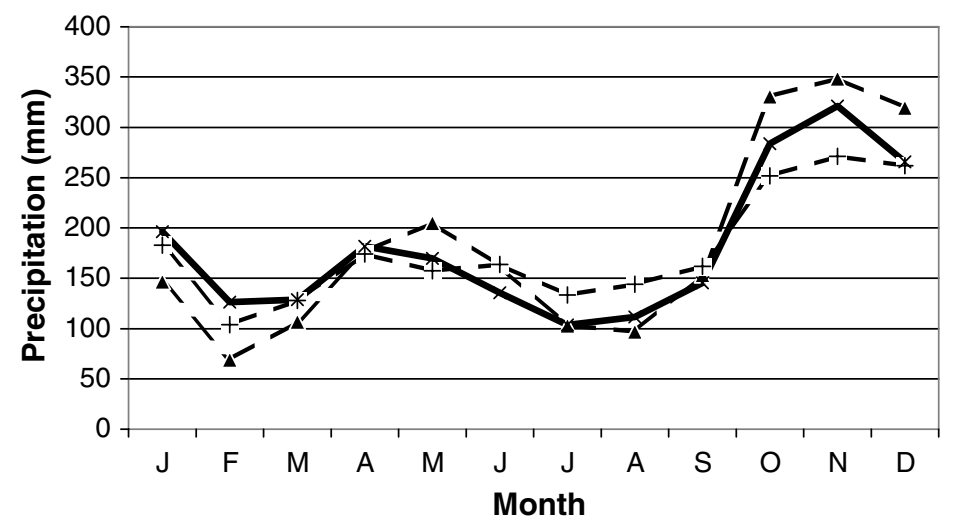

-^-El Nino-+-La Nina—Normal

Figure 7. The rainfall climatology in the rice-producing areas of Sri Lanka when El Niño, normal and La Niña phases prevailed between 1869 and 1998

In the 1973-74 La Niña Maha season there was an increase in production notwithstanding the normally lower rainfall, as the state reduced fertilizer prices and encouraged an increase in the area under cultivation. During 1984-85, farmers increased the acreage under cultivation owing to poor harvests in the previous Maha (Central Bank, 1985).

The inter-annual departures for Maha yield (Figure 9) are similar to those for the fractional production anomalies (Figure 8) except in 1957-58, 1986-87 and 1987-88. Differences between anomalies in production and yield are due to unforeseen impacts that may wipe out some of the cultivated areas, such as the floods that happened in 1957-58. The cyclones during the Maha of 1963-64 and 1977-78 (Somasekeram et al., 1988) in the northeast of the island have had no discernible impact on island-wide rice production.

\subsection{Rice production variability in Yala}

The Yala production anomaly (Figure 10) does show a significant correlation $(r=0.29)$ with April-June (AMJ) rainfall (Table V). The correlation of the rice production anomaly with the concurrent NINO3.4 index $(r=0.40)$ is stronger than that with rainfall. The Yala production anomaly shows a strong correlation with 


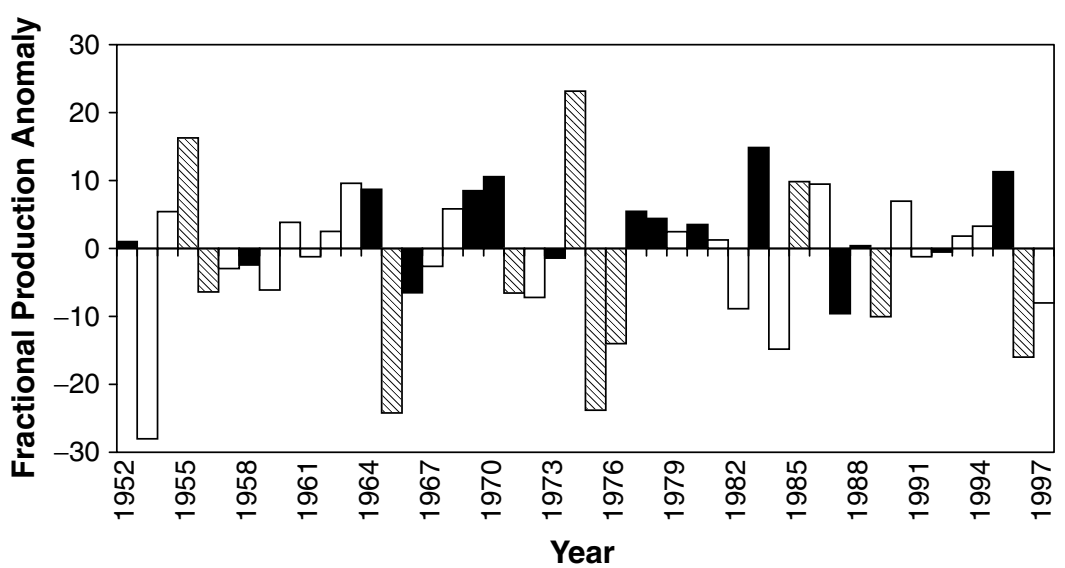

Figure 8. The inter-annual variation in the Maha fractional rice production anomaly, which is computed as the departure of the seasonal rice production from the trend and also normalized by the 5 year mean value. The trend is estimated as the 5 year running mean as shown in Figure 4. El Niño years are indicated as solid bars and La Niña years are indicated as hatched bars

Table III. Correlations of the Maha rice production anomaly with rainfall and NINO3.4 during the concurrent season and with the previous Yala for the period from 1952 to $1997 ; n=45$

\begin{tabular}{llcc}
\hline Correlation of Maha production anomaly with: & \multicolumn{2}{c}{ Correlation coefficient } \\
\cline { 3 - 4 } & & Rainfall & NINO3.4 \\
\hline \multirow{2}{*}{ Previous Yala } & AMJJAS & -0.22 & 0.20 \\
& Previous AMJ & -0.03 & 0.11 \\
\multirow{3}{*}{ Maha } & Previous JAS & -0.26 & 0.24 \\
& ONDJFM & $\mathbf{0 . 2 8}$ & 0.27 \\
& OND & $\mathbf{0 . 4 6}$ & $\mathbf{0 . 2 9}$ \\
& JFM & -0.08 & 0.24 \\
\hline
\end{tabular}

Correlations of 0.28 and 0.37 are significant at $5 \%$ and $1 \%$ respectively. Correlations that are significant at $5 \%$ are shown in bold.

Table IV. Summary of variation in rainfall, production anomalies, fractional production anomalies and yield anomalies in the El Niño and La Niña seasons for the period from 1952 to 1997

\begin{tabular}{llll}
\hline Season & Anomaly & \multicolumn{1}{c}{ El Niño seasons } & La Niña seasons \\
\hline Maha & Rainfall & Rise in 10 out of 15 & Drop in 7 out of 10 \\
& Production & Rise in 10 out of 15 & Drop in 7 out of 10 \\
& Yield & Rise in 12 out of 15 & Drop in 7 out of 10 \\
Yala & Rainfall & Drop in 8 out of 14 & Rise in 6 out 8 \\
& Production & Drop in 10 out of 14 & Rise in 6 out of 8 \\
& Yield & Drop in 7 out of 14 & Rise in 5 out of 8 \\
\hline
\end{tabular}

the previous Maha rainfall $(r=0.60)$. This is due to the water availability for Yala cultivation being affected by carryover irrigation storage and groundwater recharge from the previous Maha.

In six out of eight La Niña seasons, the Yala rainfall decreased with the exceptions of 1954 and 1956 (Figure 9). There was a rise in Yala production in six out of eight La Niña years (Table IV), with 1956 and 1975 


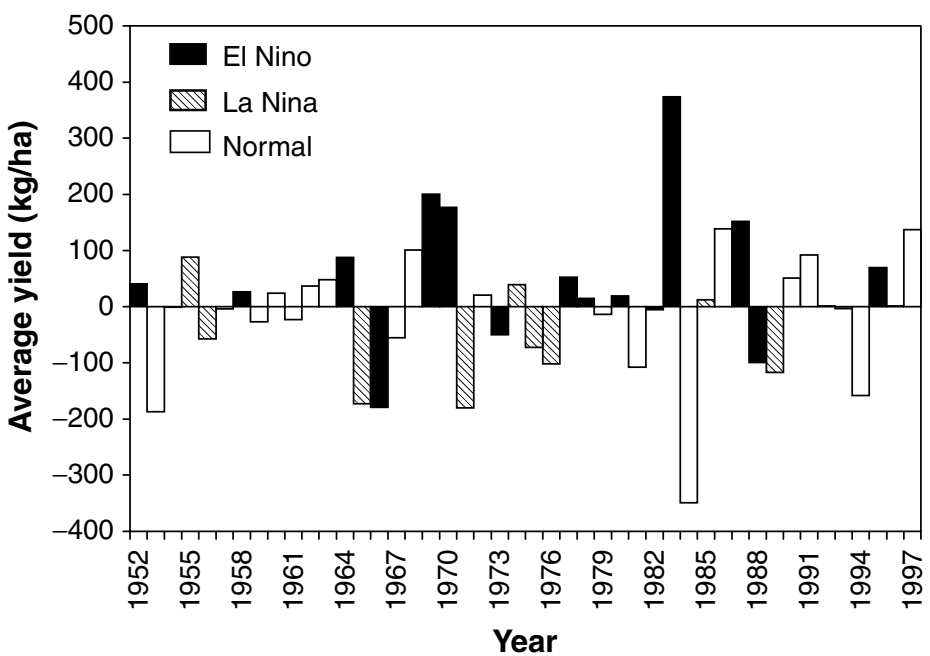

Figure 9. The inter-annual variation in the Maha rice yield anomaly computed as the difference between the yield and the 5 year running mean of yield in a given season. El Niño years are indicated as solid bars and La Niña years are indicated as hatched bars

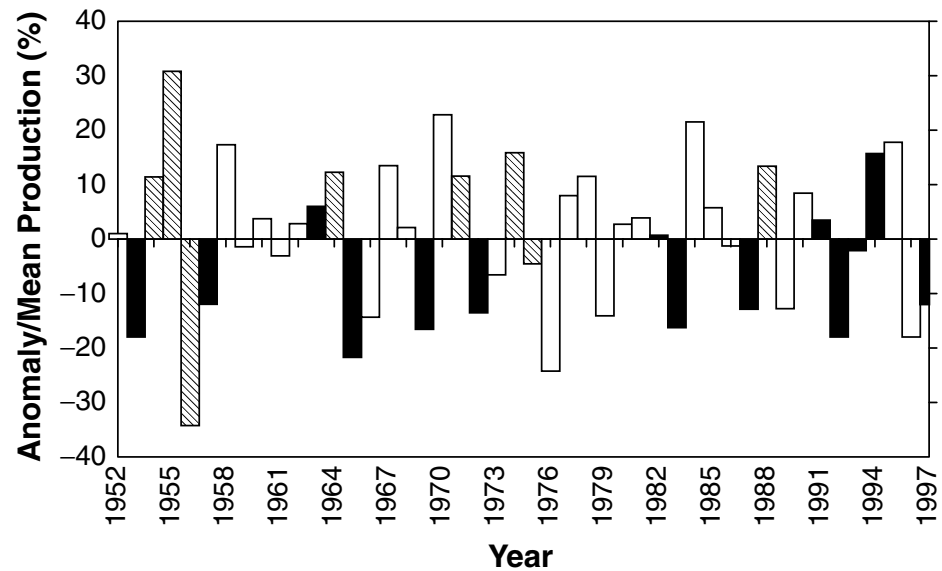

Figure 10. The inter-annual variation in the Yala fractional rice production anomaly, which is computed as the production deviation from the trend normalized by the 5 year mean production. The trend is estimated as the 5 year running mean as shown in Figure 4

being the exceptions. In addition to the decline in rainfall in 1956, civil disturbances also contributed to a drop in production. Although the rainfall was slightly above average in 1975, the application of fertilizer declined by $40 \%$ compared with the previous year subsequent to the rapid escalation of petroleum prices (Central Bank, 1975). During Yala, farmers may opt to cultivate shorter-term (3-4.5 months) varieties commencing late into the season. Thus, even if there is rainfall in the latter part of the season, farmers are still able to cultivate.

The inter-annual departures for Yala yield (Figure 11) differ from those for the fractional production anomalies (Figure 10) in a number of years, such as 1954, 1969, 1981, 1982, 1983, 1987 and 1991. Differences between anomalies in production and yield are due to unforeseen impacts that may wipe out some of the cultivated areas, such as droughts. The Yala season cultivation is more vulnerable to drought and other such anomalies. 
Table V. Correlations of the rice production anomaly during Yala with rainfall and NINO3.4 during the concurrent season and with the previous Maha for the period from 1952 to $1997 ; n=45$

\begin{tabular}{lllr}
\hline \multirow{2}{*}{ Correlation of Yala production anomaly with: } & \multicolumn{2}{l}{ Correlation coefficient $r$} \\
\cline { 3 - 4 } & & Rainfall & NINO3.4 \\
\hline \multirow{2}{*}{ Previous Maha } & ONDJFM & $\mathbf{0 . 6 1}$ & -0.01 \\
& Previous OND & $\mathbf{0 . 3 8}$ & 0.07 \\
\multirow{3}{*}{ Yala } & Previous JFM & $\mathbf{0 . 5 4}$ & -0.12 \\
& AMJJAS & 0.21 & $\mathbf{- 0 . 4 0}$ \\
& AMJ & $\mathbf{0 . 2 9}$ & $\mathbf{- 0 . 3 6}$ \\
& JAS & 0.02 & $\mathbf{- 0 . 3 8}$ \\
\hline
\end{tabular}

Correlations associated with significance levels at $5 \%$ and $1 \%$ are 0.28 and 0.37 . Correlations that are significant at $5 \%$ are indicated in bold.

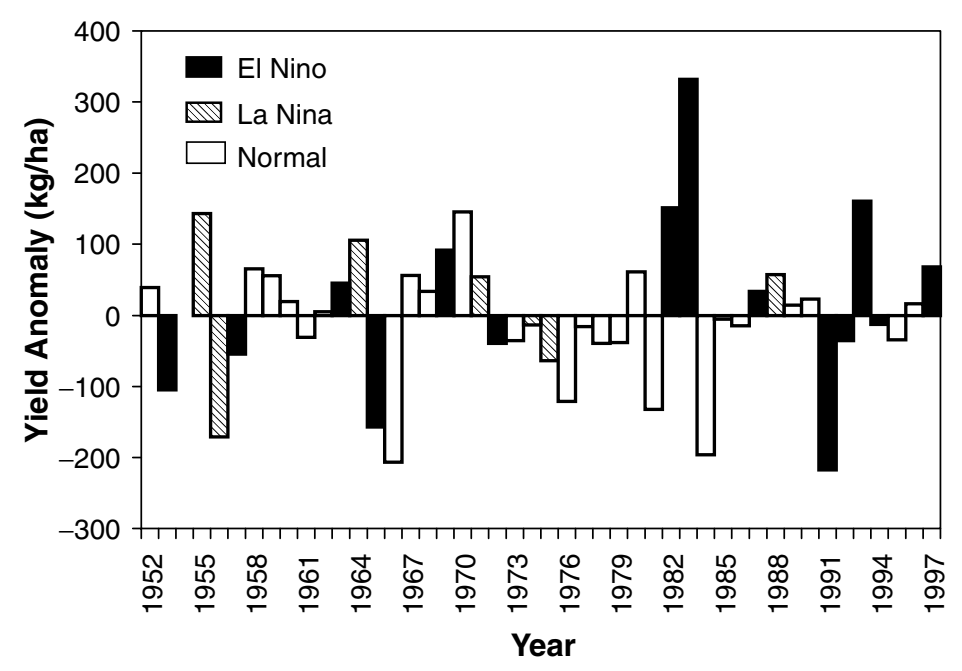

Figure 11. The inter-annual variation in the Yala rice yield anomaly computed as the difference between the yield and the 5 year running mean yield in a given season. El Niño years are indicated as solid bars and La Niña years are indicated as hatched bars

\section{CONCLUSIONS AND DISCUSSION}

\subsection{ENSO, rainfall and rice production}

El Niño conditions lead to an increase in the average Maha rice production and a decline in that of Yala. The rainfall anomalies during Maha were most pronounced during the first few months when water is needed for the growth of the rice plants. However, the Maha cultivation during El Niño is vulnerable to flooding. The Maha rice production anomalies showed statistically significant correlations with both rainfall $(r=0.46)$ and NINO3.4 ( $r=0.29)$ during the OND period.

The Yala production anomalies showed a stronger relationship with the NINO3.4 index $(r=0.40)$ than with rainfall $(r=0.21)$. In addition, the Yala rice production anomaly shows a strong correlation $(r=0.60)$ with the previous Maha rainfall, underlining the influence of carryover storage and groundwater recharge.

The ENSO relationships described above for both Yala and Maha rice production are shown to hold in 33 out of 47 seasons with extreme ENSO conditions. In 9 of the 14 instances where this prognosis was incorrect, factors such as floods and anomalies in the previous season's production, fertilizer subsidies and guaranteed rice purchasing prices were found. 


\subsection{Use of ENSO forecasts for agricultural management}

Seasonal climate forecasts are needed by early March for Yala and early September for Maha. During this period, the acreage of rice that is to be cultivated, the type of rice variety that is to be used and the choice of crops are deliberated upon by farmer groups, district cultivation managers and water managers. For example, during seasons where El Niño is predicted, farmers may choose flood-resistant varieties in Maha and drought resistant short-term varieties in Yala. In addition, the planting date could be delayed. Irrigation managers may increase the carryover storage to tide over water deficits in the January to April period.

ENSO-based forecasts will be far from perfect, and farmers, irrigation managers and others who could use it for agricultural decision-making should be well aware of it. The challenge in the successful use of probabilistic ENSO forecasts is the communication of the level of uncertainty to farmers and water managers and the choice of steps that will minimize financial losses in case the predictions are incorrect.

\subsection{Use of ENSO forecasts for agricultural policy-making}

Policies affecting rice production, such as large-scale irrigation, guaranteed price schemes, fertilizer pricing, state purchases and storage, customs duties on rice imports and land use, are based on interpretation of trends for rice production. Retrospective interpretation of the impact of ENSO events on perceived trends may be useful. For example, there appears to be a declining trend in rice production from 1971 to 1976 . But, this drop should be interpreted in the light of seven La Niña seasons, three normal seasons and two El Niño seasons falling within those 6 years.

An example of state intervention was in late 1988, when the fertilizer subsidy given to farmers was withdrawn following increased production of rice in previous seasons. However, the high production in 1988 may have been due to an El Niño Maha of 1987-88 and a La Niña Yala of 1988. Production dropped considerably after the subsidy was withdrawn and normal NINO3.4 conditions prevailed. The subsidy had to be reintroduced after production dipped.

Since, the relationship between ENSO and rice production in Sri Lanka is reversed from Maha to Yala, the most vulnerable circumstance in terms of food security is when an El Niño Yala season is succeeded by a La Niña Maha or vice versa.

\section{ACKNOWLEDGEMENTS}

Data used in this study were obtained from the Departments of Agriculture and Meteorology in Sri Lanka. Part of the work reported was carried out at the Institute of Fundamental Studies, Kandy, Sri Lanka, with Suganda Somasundera. Thereafter, this work was supported by a fellowship at the International Research Institute for Climate Prediction administered by the University Consortium for Atmospheric Research. The climatic analysis is based upon work conducted with Chet Ropelewski. Detailed comments by Jim Hansen and a referee are gratefully acknowledged, along with useful discussions with Gamini Seneviratne and Ranjith Punyawardena.

\section{REFERENCES}

Cane MA, Zebiak SE. 1985. Experimental forecasts of El Niño. Nature 321: 827-832.

Cane MA, Eshel G, Buckland RW. 1994. Forecasting Zimbabwean maize yield using eastern equatorial Pacific sea surface temperature. Nature 370: 204-205.

Central Bank. 1958. Annual Report. Central Bank of Sri Lanka, Colombo.

Central Bank. 1966. Annual Report. Central Bank of Sri Lanka, Colombo.

Central Bank. 1973. Annual Report. Central Bank of Sri Lanka, Colombo.

Central Bank. 1975. Annual Report. Central Bank of Sri Lanka, Colombo.

Central Bank. 1985. Annual Report. Central Bank of Sri Lanka, Colombo.

Department of Census and Statistics. 1991. Statistical Abstract of the Democratic Socialist Republic of Sri Lanka, Colombo.

Domroes M. 1974. The Agroclimate of Sri Lanka. Franz Steiner Verlag Gmbh: Wiesbaden.

Gadgil S. 1996. Climate change and agriculture. In Climate Variability and Agriculture. An Indian Perspective, Abrol YR, Gadgil S, Pant GB (eds). Narosa: New Delhi, India; 1-18.

Hansen JW, Hodges AW, Jones JW. 1998. ENSO influences on agriculture in the south-eastern united states. Journal of Climate 11: 404-411. 
Kane RP. 1998. ENSO relationship to the rainfall of Sri Lanka. International Journal of Climatology 18(8): 859-872.

Kaplan A, Cane MA, Kushnir Y, Clement AC, Blumenthal MB, Rajagopalan B. 1998. Analyses of global sea surface temperature: 1856-1991. Journal of Geophysical Research 103: 18 567-18589.

Leaker A. 1984. An investigation of the factors affecting paddy yields from two districts. Journal of the National Science Council of Sri Lanka 12(1): 71-92.

Parathasarthy B, Munot AA, Kothawale DR. 1988. Regression model for estimation of Indian food grain production from Indian summer monsoon rainfall. Agricultural and Forest Meteorology 42: 167-182.

Phillips JG, Cane MA, Rosenzweig C. 1998. ENSO, seasonal rainfall patterns and simulated maize yield variability in Zimbabwe. Agricultural and Forest Meteorology 90: 39-50.

Punyawardena BVR, Cherry NJ. 1999. Assessment of the predictability of the seasonal rainfall in Ratnapura using southern oscillation and its two extremes. Journal of the National Science Council of Sri Lanka, 27(3): 187-195.

Rasmusson EM, Carpenter TH. 1983. The relationship between eastern equatorial Pacific sea surface temperature and rainfall over India and Sri Lanka. Monthly Weather Review 110: 354-383.

Ropelewski CF, Halpert MS. 1987. Global and regional scale precipitation patterns associated with the El Niño/southern oscillation. Monthly Weather Review 115: 1606-1626.

Ropelewski CF, Halpert MS. 1989. Precipitation patterns associated with the high index phase of the southern oscillation. Journal of Climate 2(3): 268-284.

Seneviratne G, Van Holm LHJ. 1996. Green manure and rice straw recycling potentials in rice of Sri Lanka: a review. In Proceedings of the Workshop on Biological Nitrogen Fixation, Institute of Fundamental Studies, 1996. 1-13.

Somasekeram T, Perera LAG, Perera MP, De Silva BG, Karunanayake MM, Epitawatta DS. 1988. National Atlas. Survey Department: Colombo.

Sumathipala WL, Punyadeva NBP. 1998. Variation of the rainfall of Sri Lanka in relation to El Nino. In Proceedings of the Annual Sessions of the Institute of Physics, Sri Lanka, Colombo.

Suppiah R. 1997. Extremes of the southern oscillation and the rainfall of Sri Lanka. International Journal of Climatology 17(1): 87-101.

Suppiah R. 1998. Spatial and temporal variations in the relationship between the southern oscillation and the rainfall of Sri Lanka. International Journal of Climatology 16(12): 1391-1408.

Suppiah R, Yoshino MM. 1986. Some agroclimatological aspects of rice production in Sri Lanka. Geographical Review of Japan, Series B 59(2): 137-153.

Trenberth KE. 1997. The definition of El Niño. Bulletin of the American Meteorological Society 78(12): 2771-2777.

Yoshino MM, Suppiah. R. 1983. Climate and paddy production: a study on selective districts in Sri Lanka. In Climate, Water and Agriculture in Sri Lanka, Yoshino MM, Kayane I, Madduma Bandara CM (eds). Institute of Geoscience, University of Tsukuba: Tsukuba, Japan.

Yoshino MM, Ichikawa T, Urushibara K, Nomoto S, Suppiah R. 1983. Climate fluctuation and its effect on paddy production in Sri Lanka. Climatological Notes. Institute of Geoscience, University of Tsukuba: Tsukuba, Japan; 33: 9-32. 